\title{
El Habitus académico como generador de resistencias en las profesoras
}

\author{
Academic Habitus as generator of resistances
}

in women professors

\section{Luis Enrique Meléndez-Ferrer ${ }^{1}$}

\section{Resumen}

Las resistencias en profesoras se producen por formas-sentidos que perpetúan el habitus académico. Este abordaje comprende el habitus académico mediante el discurso dominador universitario y en las consciencias colectivas de las profesoras. Este habitus se concreta en resistencias del lenguaje estructural reflejado en significados normativos, filosóficos y pragmáticos alienantes del discurso heteronormativo universitario. El método para construir el ensayo se basó en el análisis documental y hermenéutico. El habitus académico petrifica interacciones sociales, mantiene la dicotomía: objetividad-subjetividad, define al sujeto, fortalece prácticas culturales, entiende el ethos masculino, sincroniza actitudes de profesoras, valora disposiciones morales, descubre la obligación política para ser/actuar, revela el respeto por el status quo de profesoras ante la dominación de la universidad y la profesión académica.

Palabras clave: Habitus académico, profesoras, identidades, resistencias.

\footnotetext{
${ }^{1}$ Investigador del Centro de Documentación e Investigación Pedagógica (CEDIP), Facultad de Humanidades y Educación, La Universidad del Zulia (LUZ), Venezuela. Docente de la Escuela de Psicología, Universidad Bicentenaria de Aragua (UBA), Venezuela. Email: lemelendezferrer@gmail.com
} 


\begin{abstract}
Resistances in female professors are produced by forms-senses that perpetuate the academic habitus. The approach comprises the academic habitus through the dominant university discourse and the collective consciousness of female professors. Such habitus are expressed in the structural language reflected in normative, philosophical, and pragmatic meanings alienated from the heteronormative university discourse. It is a method of documentary and hermeneutic analysis for an essay. The academic habitus petrifies social interactions, maintains the dichotomy: objectivity-subjectivity, defines the subject, strengthens socio-cultural practices, understands the male ethos, synchronizes attitudes, values moral dispositions, discovers the political obligation to be/to act, reveals respect for status quo of female professors in front of the domination of the university and the academic profession.
\end{abstract}

Key words: Academic Habitus, female professors, identities, resistances.

\title{
1. Introducción
}

Este ensayo invita al diálogo sobre la resignificación del habitus académico como categoría de poder, desde la cual se originan las resistencias como identidades de las profesoras y como aquello delimita el contexto cultural, profesional e institucional en la universidad pública, nacional y autónoma. Tal diálogo es el espacio para el debate pro-feminista, revelador de críticas a las definiciones y características del habitus. Esto se contextualiza en las subjetividades, intersubjetividades y corporalidades de las mujeres docentes, científicas e intelectuales, generando así, resistencias en ellas. Resistencias dirigidas a darle sentido y cuerpo a las identidades expresadas en sus prácticas sociales e institucionales cotidianas que se desarrollan en la ejecución de sus funciones esenciales en la universidad; institución que tiende a considerar, cada vez más, una reforma educativa y organizacional neoliberal. 
El ensayo pretende comprender el habitus académico mediante el reconocimiento del discurso dominador universitario que se encuentra en la consciencia colectiva de las profesoras, siendo esto un elemento productor de resistencias en sus modos identitarios de vidas y en las funciones esenciales en la universidad. Este debate produce un ensayo basado en algunos principios del análisis documental y hermenéutico, los cuales se consideran desde variadas perspectivas teóricas, a saber: sociología, filosofía feminista, psicología social, educación, urbanismo, epistemología, teorías de género e identidades de géneros y comunicación social.

Lo manifestado es necesario al construir un ensayo crítico, reflexivo y situacional, con la intención de crear contrastaciones entre epistemes y praxis, el incitar cambios estructurales de la dominación masculina en la universidad e impulsar la construcción de identidades libertarias en contra del neoliberalismo emplazado en las interacciones productivas de las actoras mencionadas.

Se considera, entonces, que las resistencias de las profesoras se originan con estéticas uniformes y sentidos unívocos, perpetuando las identidades profesorales que constituyen el habitus académico en el colectivo social de la universidad. La acepción del habitus planteado, deviene de conceptualizarlo como las predisposiciones, esquemas de percepción y expectativas establecidas permanentemente, desde lo cual se organizan las instituciones educativas. Por esto, se reconoce un habitus institucional, entendido como la fuerza que empuja y orienta las intersubjetividades, entre esas, la expectativa de la comunidad profesoral hacia una dirección particular (Tarabini, Curran y Fontdevila, 2015).

Las resistencias se desarrollan en las funciones esenciales del mundo universitario, vislumbradas en las prácticas cotidianas de las mujeres docentes, científicas e intelectuales. Asimismo, se originan en las bases estructurales y pragmáticas de discursos gerenciales e institucionales neoliberales de la universidad, en donde se han gestado social, material e históricamente en las sociedades occidentales. 
El habitus académico se concreta en resistencias institucionales emergentes desde un lenguaje estructural reflejado y sustentado en significados normativos, jurídicos, legales, filosóficos, pragmáticos y teleológicos alienantes del discurso heteronormativo universitario. Según Morán (2017), este discurso es la herencia de códigos patriarcales que configuran la cultura hegemónica, la cual posee elementos heteropatriarcales que no son exclusivos de los hombres. Existe, en efecto, un activismo heteropatriarcal que ha permeado la cultura latinoamericana. Por tanto, tal activismo se transforma en una agenda de poder y dominación para la intervención política y social.

En efecto, el habitus académico origina resistencias metadiscursivas sobre las racionalidades, emocionalidades, corporalidades e interacciones sociales de las profesoras. Esto reproduce las resistencias -como identidades- tendientes a subordinar masculinamente, a apegarse y someterse con la estructura laboral, contractual y organizacional; visualizada como única y legítima en la universidad con pensamiento burgués y neoliberal.

Dicho habitus es la fuerza heterosexual en la gestación de resistencias, porque incorpora el discurso patriarcal creado por las estructuras simbólicas y materiales de las instituciones del Estado-nación. Este sentido discursivo, el patriarcado es un sistema de relaciones de poder reproducido socialmente, para normalizar a los cuerpos sexuados mediante un código binario. Esto posiciona a las mujeres en un lugar inferior y/o restringido respecto de los hombres (Morán, 2017).

Las estructuras se concretan en las rutinas productivas, funciones académicas, diseños organizacionales y en los modelos gerenciales de la universidad, para oprimir a las profesoras. Esto ocurre porque son consideradas como sujet(o)s sujetados a la cultura científica. Las características del habitus se materializan en resistencias particulares en sus intersubjetividades, cuerpos y prácticas sociales e identitarias durante la ejecución de las funciones universitarias. Las resistencias, desde la lógica identitaria, se instauran en este contexto histórico, cultural e institucional; porque se ha construido socialmente 
que, a las profesoras son seres humanos a quienes se les atribuye una identidad de género liberal. Tal discurso identitario obliga a concebirlas desde su condición física y política de ser mujer (por su razón sexual-anatómica); así, ellas deben estar apegadas a la racionalidad heteronormativa. Con esto, ellas son discriminadas identitariamente, ya que actúa la fuerza de la lógica machista universitaria.

El habitus configura resistencias para subyugar a las mujeres docentes, científicas e intelectuales. Esto se genera mediante la reproducción de procedimientos técnico-administrativos que diseñan, sistematizan, controlan y castigan sus interacciones productivas, por ejemplo: la postergación en la aprobación del cambio de dedicación profesoral, el retardo en el cambio del estatus en el escalafón profesoral, así como, la aplicación de dificultades administrativas o académicas o la desaprobación de trabajos de ascenso. Para ir en contra de estas interacciones, se exige que las profesoras se vinculen con modelos evaluativos de perfiles predeterminados expuestos en los cargos, funciones y tareas del profesorado, con la intención de minimizar tales habitus de dominación institucional.

La definición de habitus, instaurada por Bourdieu (1980), se entiende como el conjunto de

sistemas de disposiciones duraderas y transferibles, estructuras estructuradas predispuestas a funcionar como estructuras estructurantes, es decir como principios generadores y organizadores de prácticas y de representaciones que pueden estar objetivamente adaptadas a su fin sin suponer la búsqueda consciente de fines ni el dominio expreso de las operaciones necesarias para alcanzarlos, objetivamente 'regladas' y 'regulares' sin ser en nada el producto de la obediencia a reglas y, siendo todo esto, colectivamente orquestadas sin ser el producto de la acción organizadora de un director de orquesta. (p. 88-89)

Con esto se interpreta que la comprensión de resistencias como huellas identitarias del habitus académico en las profesoras, surge desde cuatro dimensiones. Estas últimas se definen a partir de la estructuración dialógica de 
temas, lo cual se hace para resumir, organizar y conglomerar el resultado del análisis discursivo aplicado a las lecturas realizadas en pos de constituir este ensayo. Las dimensiones establecidas para tal fin, refieren al sistema de interacciones sociales, a la estructura de objetividad y subjetividad(es), a la construcción de sujeto con una ontología dialógica entre lo social e individual y, por último, al conjunto de prácticas socioculturales.

\section{Desarrollo}

\subsection{El Habitus como sistema de interacciones sociales ante las resistencias de las profesoras}

Las resistencias se gestan mediante un habitus considerado como el sistema de interacciones sociales, constituido por tres elementos fundamentales, a saber: disposición, inclinación e incorporación.

El habitus aprehende el término disposición, porque "...parece particularmente apropiado para expresar todo lo que recubre el concepto de habitus" (Bourdieu, 1999, p. 95). Dicho concepto promueve a las profesoras a visibilizar subjetividades e intersubjetividades sobre sus resistencias, en términos de identidades de rechazo o aceptación. Tales significaciones se originan en torno a la esfera: científica, educativa, laboral, gremial, religiosa, partidista, organizacional, gerencial, científico y disciplinar. Esferas en las que ellas están sumergidas al entretejer sus prácticas universitarias.

Se entiende que el habitus es un sistema de disposiciones (Bourdieu, 1999), conceptualizándose como un aparato académico que sincroniza las actitudes e identidades. Esto es el espacio óntico y epistémico que revela lo cognitivo, lo afectivo-emocional y lo conativo de las profesoras en sus relaciones productivas universitarias.

Así, el habitus académico genera resistencias al instalar -mediante una aceptación ideológica- un aparato sociosimbólico y cultural que mecaniza las ideas, creencias, tradiciones, cuerpos así como las formas de crear ciencia, saberes y producciones institucionales con la episteme de mujeres docentes, 
científicas e intelectuales. Una interpretación sobre este tipo de habitus, es manifestada por Rizo y Rodríguez (2016), quienes, en palabras de Gilberto Giménez Montiel, exponen que hay varios habitus científicos, según los diferentes campos de acción práctica. Por esto, el habitus de un científico (en este caso: las profesoras) depende de su trayectoria, de su inserción en el campo disciplinar, de la posición generada a partir del competir en el mismo espacio, del capital simbólico acumulado y de las posibilidades emergentes en tal campo para alcanzar una posición. Con todo lo expuesto, el científico acumula disposiciones en pro de competir y orientar sus prácticas y sus decisiones.

Lo expuesto impone una lógica lineal, homogénea y sistematizada de poder sobre la vida de los grupos sociales universitarios; reforzando así, la permanencia de discursos hegemónicos y neoliberales en la conciencia colectiva y rechazando la episteme antipatriarcal o episteme feminista creada para oponerse a la cultura científica. Por esto, la oposición y desaprobación está motivada porque surge la episteme feminista. Esta se interesa en reconocer las subjetividades, mediante la inclusión de teorías con dimensiones relegadas, entre esas: las emociones, los deseos y los cuerpos; es decir, las experiencias. Así, esta episteme abre nuevos campos de reflexión teórica y metodológica cimentados en desvelar al otro como sujeto y no como objeto de conocimientos y saberes, porque se le da relevancia a la diversidad de sujetos, experiencias y prácticas sociales (Tabares, 2019).

Además, el habitus es un ethos, un conjunto interrelacionado de disposiciones morales. Esta mirada asume un elemento simbólico e histórico que constituye el sentido de una sola ética y una sola política. Ambos sentidos son incólumes e incuestionables en la vida, episteme y en el sentido óntico de las identidades de las profesoras durante el despliegue de sus funciones universitarias. Por tanto, el habitus académico es la fuerza de un solo ethos masculino, promotor de resistencias neoliberales en las actoras mencionadas.

Con lo anterior, ellas se sienten política y éticamente, obligadas a aceptar el sistema modulador y legítimo que reproduce un discurso hegemónico y heteronormativo mediante la ejecución de la ciencia, profesionalización, gerencia 
universitaria, entre otras estrategias de docilización de los cuerpos. Con Moyano y Durango (2016), se desvela una perspectiva comprensiva acerca de dicho discurso, la cual esboza que el discurso heteronormativo, es un evento comunicativo que predispone el imaginario colectivo. Acá, lo correcto es lo conocido y lo que política y moralmente es bien visto ante un colectivo social. Por esto, es necesario que el sujeto (en este caso: las profesoras) tenga conceptos preconcebidos y previamente aceptados como útiles, tales como identidad de género, según la normatividad y naturalización de lo preestablecido, sin salirse de los límites de la noción de hombre o mujer, instaurada.

Aunadamente, el habitus es una aisthesis, un sistema de gustos y disposición estética. Por esto, el habitus académico es un aparato creador de resistencias en las profesoras, al instaurar subjetividades emocionales controladoras frente a las funciones académicas y organizacionales, así como también, hacia los conceptos esencialistas de la universidad.

Tal habitus es un mecanismo cultural para que las actoras referidas instauren valoraciones aprehensivas, reactivas o de repulsión ante discusiones, posturas epistémicas y prácticas metodológicas de la ciencia, educación y gerencia universitaria. Por ser un dispositivo productor de resistencias, impone una estética social consensuada y cargada con la identidad de una visión e intención patriarcal. Esta estética domina, reduciendo las intersubjetividades diferentes de las mujeres docentes, científicas e intelectuales ante la fuerza del discurso de la universalidad y la estética heteronormada.

Así, se crea una racionalidad, moralidad e interacción social con una sola estética social y productiva en la universidad. Según Moyano y Durango (2016), revelan que dicha forma homogénea y dominante, se sustenta en que el contexto escolar, se encuentran discursos heteronormativos. Estos tienden a restringir la comprensión y aprehensión de las realidades holísticas, desde la cual se incluyan aspectos relativos a la identidad de género, a la identidad sexual y a las preferencias sexuales. 
Según Rizo (2006) el habitus es el conjunto de disposiciones duraderas. Desde la mirada académica, este concepto genera una red de prácticas sociales para sostenerlas en el tiempo social, en el tiempo cronológico, en las estructuras ideológicas y conceptuales de las instituciones societales, así como también, para encarnarlas en huellas sobre los cuerpos de los colectivos humanos. El habitus académico revela ideas-acciones (identidades) consolidadas y originadas con la finalidad de perpetuarse progresivamente, en las historias cotidianas del rendimiento laboral de las profesoras, en sus modos de interactuar en los grupos humanos así como, en las visiones y métodos de gestión de la universidad.

Dicho habitus es un sistema abierto de disposiciones confrontadas, permanentemente, con experiencias nuevas $y$, por lo mismo, es afectado por ellas. Es un sistema de construcción de resistencias tendiente a ser abierto, crítico, constrastante y sensible de racionalidades, emocionalidades, corporalidades e interacciones socioproductivas de las profesoras. Todo esto rompe discursos fuertes para minimizar la rigidez de las estructuras institucionales e históricas que dominan los sentidos y las formas al crear ciencia, profesionalizar, establecer mecanismos de relación con gremios partidistas y disciplinares e instaurar planes de gobierno.

Rizo y Rodríguez (2016) consideran que el habitus académico se asocia a la existencia de diversos condicionantes para que al profesorado, -en este caso: a las profesoras- se les identifique como investigadoras sociales, es decir, como un sujeto científico. Esto ocurre por la competencia neoliberal presente en el campo de trabajo organizacional y profesional, así como también, por la desigual distribución de capitales académicos, científicos, sociales, simbólicos en la universidad.

Como segundo elemento fundamental, la inclinación vislumbra que el habitus es una propensión hacia algo específico (Bourdieu, 1999). Esto implica una actitud aproximativa ante una situación u objeto preestablecido, es decir, un sistema psicosocial y académico cargado de una fuerza que acerca a las profesoras hacia un punto antiguo, oculto, reformado o nuevo (un objeto 
simbólico de beneficio y conveniencia) en su cotidianidad educativa, laboral, política, gerencial, disciplinaria, religiosa, gremial, entre otras esferas.

No se garantiza que tal acercamiento llegue a un fin único, determinado, estático y, sobre todo, satisfactorio para las mujeres docentes, científicas e intelectuales. Esto plantea las posibles propensiones intersectadas por otras inclinaciones. $\mathrm{O}$, en cambio, se expone las posibles inclinaciones que desvíen, absolutamente, las intenciones iniciales de aproximarse a un objeto o situación universitaria.

Por tanto, el habitus académico produce resistencias neoliberales que invita a la apropiación de ambientes y al posicionamiento en ciertos escenarios públicos de poder (gerencia y gobierno), a que las profesoras sean reconocidas por su productividad, a participar en grupos y eventos científicos, a involucrarse activamente en la investigación, etc. Tal habitus implica que ellas ensamblen, contradictoriamente, resistencias en pos de vincularse con situaciones u objetos sociales dentro o fuera de la universidad, estructurando una transgresión e irrespeto. 0 , sencillamente, les empuja a desapegarse (acción contraneoliberal) de algunas situaciones u objetos sociales que no representan la atracción o interés científico, político, educativo, gerencial en la universidad.

Adicionalmente, el habitus académico es una inclinación compuesta por un hexis, es decir, por un registro de posturas y gestos en la memoria social, colectiva e histórica de los grupos humanos. En efecto, es un dispositivo creador de resistencias al institucionalizar el sentido único y la forma única de producir comportamientos socioculturales en las profesoras. Esto lleva a pensar al habitus como la lógica académica que legitima la reiteración e historia única y vertical de acciones que ellas deben ejecutar al visibilizar su concepción y práctica social, como personas intelectuales, agentes gerenciales e institucionales, militantes de partidismos políticos, etc. Por esto, el habitus sistematiza un modelo patriarcal y hegemónico neoliberal de comportamiento socioproductivo, impuesto sobre el ser y quehacer de las mujeres mencionadas. 
La configuración del modelo machista establece la uniformidad y repetición de identidades y corporalidades permanentes e inamovibles para activar la dominación universal de el hombre sobre la mujer (en singular). Asimismo, se propone la producción estética de tres elementos básicos, a saber: cuerpos, expresiones y subjetividades generizadas (masculinización) por una la mirada heterosexual; los cuales son diferentes en su concepto y en su forma aparente. Esto sitúa o distribuye a tales elementos, en distintos lugares de las tramas de poder (Morán, 2017).

Se instala, así, un sistema replicador de actitudes sociales en pro de que las profesoras desplieguen una forma única, tubular y restrictiva que domina su espontaneidad y creatividad. Esto produce la monotonía de la experiencia en el quehacer universitario e impide el surgimiento de subjetividades y prácticas sociales alternas, no convencionales, irreverentes e insurgentes opuestas a lo neoliberal.

Según Vásquez y Carrasco (2017), es urgente e indispensable repensar en un cambio -aunque sea parcial- del pensamiento heteronormativo dentro de las epistemes e interacciones socioculturales de las profesoras. Un cambio dirigido a desarticular y ajustar planteamientos conservadores, reconocidos como retrógrados en cuanto a la categoría: género y al cuerpo del sujeto social, en este caso, de las profesoras. Se expone una modificación sobre aquellos criterios normados que orientan, con sutiles y formales variaciones, el comportamiento sexual y no sexual de la corporalidad de todos los seres humanos.

Para finalizar esta primera dimensión, se devela la incorporación, como tercer elemento fundamental, al comprender el habitus académico. Según Bourdieu (1999), se reconoce que

El habitus -al ser fruto de la incorporación de principios de visión y división constitutivos de un orden social o de un campo particular- engendra prácticas inmediatamente ajustadas a ese orden, y por lo tanto, percibidas y valoradas, por quien las lleva a cabo, y también por los demás, como justas, correctas, hábiles, adecuadas, sin ser en modo alguno, consecuencia de la obediencia a un orden en el sentido imperativo, a una norma o a las reglas del derecho. ( $p$. 83) 
El habitus académico es el aparato de ajuste social emplazado por los colectivos humanos ante la producción normativa de la cultura que estos mismos establecen. Este concepto ensambla resistencias al subyugar mediante un mecanismo de coerción o ajuste social en las esferas que actúan sobre las cotidianidades de las mujeres mencionadas.

Dicho concepto se asume como el sistema que dociliza las consciencias críticas y reflexivas de las profesoras, mediante un consenso entre iguales con base en la ideología burguesa y heterosexual. Esta perspectiva filosófica e ideológica se consolida en la opresión manifestada por Morán (2017), mostrando que la heterosexualidad obligatoria refiere a los presupuestos establecidos por el discurso de la heterosexualidad, como un designio natural y universal. Esto se encubre con los códigos de clase media y blanca de la hegemonía masculina, que subyugan las sociedades para institucionalizar posiciones de dominación y subalteridad en base al cuerpo humano.

El ajuste social promueve resistencias a través del consenso explícito o implícito, con esa dinámica ambivalente. Por esto, el habitus se evidencia mediante racionalidades recursivas, discriminativas y contradictorias, visibilizando u ocultando, significados y prácticas sociales dependiendo de la conveniencia de las profesoras ante las circunstancias, escenarios sociales, tiempos cronológicos y coyunturas institucionales.

El habitus académico institucionaliza un proceso aperceptivo de las realidades construidas socialmente. Se propone ser el productor de resistencias en las profesoras, porque instaura una lógica identitaria con un sentido y un modelo heteronormativo que pretende percibir las funciones y características sustantivas de sus concepciones y maneras de vivir-convivir en las prácticas universitarias. De acuerdo a Ventura (2016), el modelo creado por la heteronormatividad contenida en el habitus, surge de la interacción comunicativa sobre el concepto de binarismo de género. Tal paradigma explica la relación estructural prevalente entre la heterosexualidad obligatoria y la gestión social de personas (las profesoras), al ubicarlas en dos categorías binarias y complementarias: hombres y mujeres. 
Dicho habitus crea resistencias para que ellas reproduzcan la estética en pos de comprenderse a sí mismas, frente a las interacciones socioproductivas y hacia los escenarios sociopolíticos de participación. Esto instala una tendencia -en ellas- a desvalorar lo que está fuera (en un mundo desconocido e infinito de posibilidades), porque se apega a las tradiciones escolásticas de la universidad, a las dinámicas históricas repetitivas de la gerencia universitaria, a los modelos petrificados de formación profesional, a los paradigmas epistémicos e ideológicos perpetuados en este contexto institucional, entre otros aspectos.

En fin, el habitus incuba resistencias para que las profesoras desarrollen diversas identidades de apropiación y alienación cultural, propia de discursos decimonónicos en sus prácticas cotidianas. Por tanto, esta dimensión se sintetiza con el Gráfico 1.

\section{Gráfico 1: El Habitus como sistema de interacciones sociales fundador de resistencias}

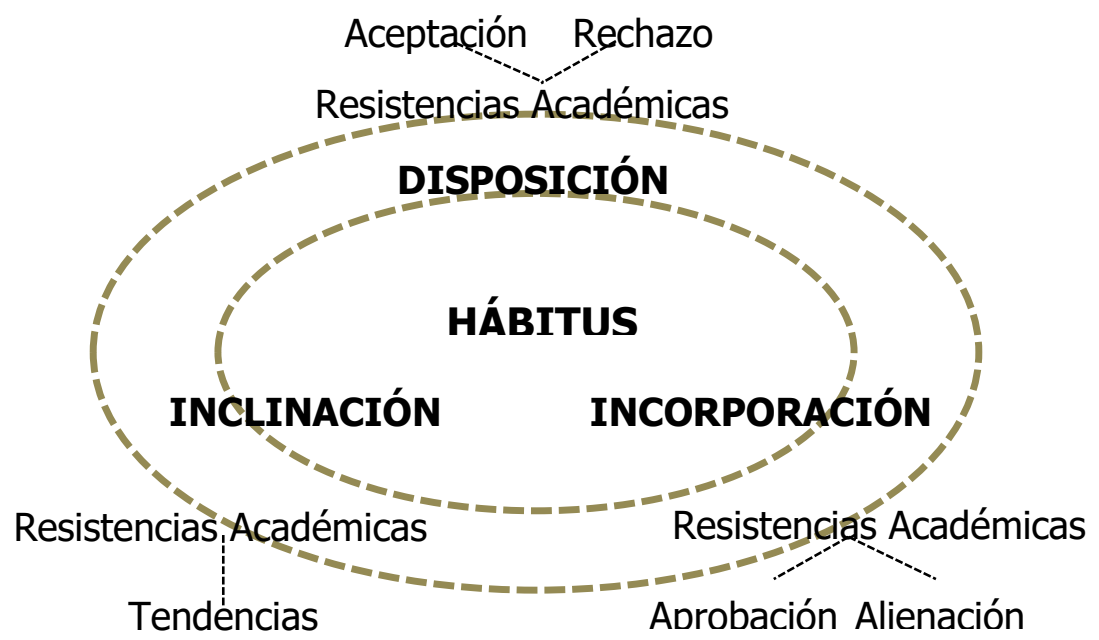

\subsection{El Habitus como estructura de objetividad y subjetividad ante las resistencias de las profesoras}

La presente dimensión se fundamenta en la polarización: objetividad vs. subjetividad, dibujadas de la noción de esquema y estructura; lo cual actúa como un conjunto sinérgico de elementos necesarios al discutir sobre el habitus. Desde 
la lógica cartesiana y positivista, el habitus es un sistema racional que legitima "la desmitificación de los criterios objetivos y la ratificación mitificada y mitificadora de las representaciones y voluntades" (Bourdieu, 1999, p. 95).

El habitus es el proceso de objetivización y subjetivización que interviene sobre varios aspectos, a saber: las experiencias situacionales y los pensamientos, corporalidades e interacciones sociales de las profesoras; las tradiciones históricas universitarias; las creencias en la gestión de las funciones laborales; las representaciones estéticas del organigrama funcional, administrativo y gubernamental de la universidad; las perspectivas epistémicas y ónticas de las ciencias que delimitan a las mujeres docentes, científicas e intelectuales a participar en una disciplina científica y en perspectivas educativas que determinan su andragogía; los sentidos y formas de tejer gremialismos partidistas, entre otros aspectos.

La bipolaridad entre objetividad y subjetividad(es), alude a una constante tensión de control entre el sujeto cognoscente y del objeto conocido en el habitus. Lo expuesto gesta resistencias con esa misma dinámica dicotómica y excluyente, en la que se desvela una tensión que domina con un solo sentido lógico-racional (flexible e inflexible), un objetivo social o subyuga las infinitas interpretaciones sobre tal sentido.

Según Gutiérrez (2004), el habitus es la objetivación o el producto de condiciones objetivas $\mathrm{y}$, también, se comprende como el capital que permite a las personas -en su cualidad de agentes- definir su comportamiento ante las nuevas circunstancias, contextos y realidades. En efecto, el habitus académico entreteje resistencias destinadas a visibilizar la materialidad de una identidad de la objetividad en signos y significados científicos, religiosos, políticos, educativas, profesionales, laborales e institucionales, generados por las profesoras.

El habitus académico es el sistema de producción social de una racionalidad que se contrapone a ciertas racionalidades y fenomenologías existentes en las acciones generadas por las actoras mencionadas durante sus funciones esenciales. Por tanto, es un camino que puede reprimir intersubjetividades académicas y 
organizacionales con sentidos comunes hegemónicos y neoliberales que condicionan sus prácticas sociales.

Otro elemento es la noción de esquema, presente en la conceptualización del habitus. Esto propone la existencia del eidos, entendido como un sistema de esquemas lógicos o estructuras cognitivas (Rizo, 2006), en el pensamiento de los colectivos humanos. El habitus, así, configura un paradigma epistémico hegemónico, interesado en subyugar otras epistemes alternas o adversarias. Paradigma cimentado en los aportes de Ventura (2016) al exponer la existencia de una racionalidad heteronormativa socialmente legitimada, naturalizada y normalizada.

Dicha racionalidad es un pensamiento hegemónico en torno a la sexualidad en un amplio sentido- que certifica y privilegia la óntica y episteme heterosexual como único modelo reconocido de interacción entre el sexo, el afecto y el parentesco. En suma, se manifiesta como el único modelo políticamente normal de conducta, impuesto sobre los seres humanos, en este caso específico, a las profesoras.

Lo expuesto instaura resistencias que defienden una forma unidireccional de producir esquemas representacionales en cuanto a varios aspectos de las prácticas universitarias, entre ellos: las teorías y métodos para hacer ciencia mediante sus investigaciones, las teorías y métodos de enseñanza-aprendizaje interesadas en desplegar la docencia, los discursos y actividades de partidismo político, la incorporación de creencias religiosas y de visiones espirituales, entre otros.

Dichos aspectos representacionales están sujetados a un esquema identitario discriminatorio, heteronormativo, burgués, elitista y cientificista; estableciéndose así, un habitus visualizado en resistencias dominantes más de orden positivista y del gran orden del discurso. Estas resistencias controlan mediante una visión única, la gestión de un esquema identitario que determina las actitudes sociales de las mujeres docentes, científicas e intelectuales.

Aunadamente, el habitus es el conjunto de patrones de clasificación que favorecen la orientación de las subjetivaciones, percepciones y acciones de las 
personas ante las realidades circunstanciales (Rizo, 2006). Por esto, el habitus académico se muestra como el productor de resistencias en la vida de las profesoras, porque se legitima en una lógica organizativa de intersubjetividades emergentes en sus prácticas y experiencias universitarias.

Dicho concepto es un camino para crear y jerarquizar significados socioculturales de la universidad, desde donde se cimientan las resistencias académicas, organizacionales como políticas en las interacciones productivas y auténticas en las actoras mencionadas.

El habitus es vislumbrado a la luz de una noción de esquema, puesto que posee una connotación más cognitivista, deviniendo de lo simbólico. Al entenderlo como esquema, se considera como una categoría con cualidades sistemáticas que explican la concordancia y la capacidad de ser transferible entre las diferentes prácticas que protagonizan las personas (Rizo, 2006).

En efecto, el habitus académico se conceptualiza como el sistema socioconstructivo de análisis crítico, reflexivo e interpretativo de complejas redes de significados. Las redes se instauran por las profesoras en sus arraigados esquemas identitarios y representacionales que desvelan su ser, pensar, convivir, coactuar en la universidad.

Como discurso de control analítico, este habitus establece resistencias que sesgan la interpretación de realidades sociales con una visión heteronormativa. Las realidades profesorales se originan y se supeditan por conceptos y métodos existentes en las esferas culturales. Esferas, en las que ellas son protagonistas y reproductoras en sus interacciones universitarias.

El último elemento a considerar en el habitus, es la noción de estructura. Según Rizo (2006, p. 2) es un sistema de disposiciones cuyo "...efecto, expresa ante todo el resultado de una acción organizadora que reviste, por lo mismo, un sentido muy próximo al de términos como estructura". Como mecanismo originador de resistencias que estructuran los modos de vida, el habitus es un camino intelectual: epistémico y pragmático que impone una estética sociocognitiva en las mujeres docentes, científicas e intelectuales. Esto visibiliza 
una estructura racional como fórmula valedera al analizar las significaciones identitarias de las realidades construidas socialmente.

Por tanto, el habitus académico es un discurso que estructura la racionalidad, corporalidad, emocionalidad e interacción social de las profesoras. Dicho discurso interactúa con la ontología, epistemología y filosofía decimonónica en pro de jerarquizar sus esquemas identitarios sobre las realidades socioculturales. Todo esto restringe las estructuras otras y analíticas, es decir, las más fenomenológicas y postestructurales. Finalmente, esta dimensión se sistematiza en la Gráfica 2.

\section{Gráfica 2. El Habitus como estructura de objetividad y subjetividad sustentador de resistencias}

\section{HÁBITUS}

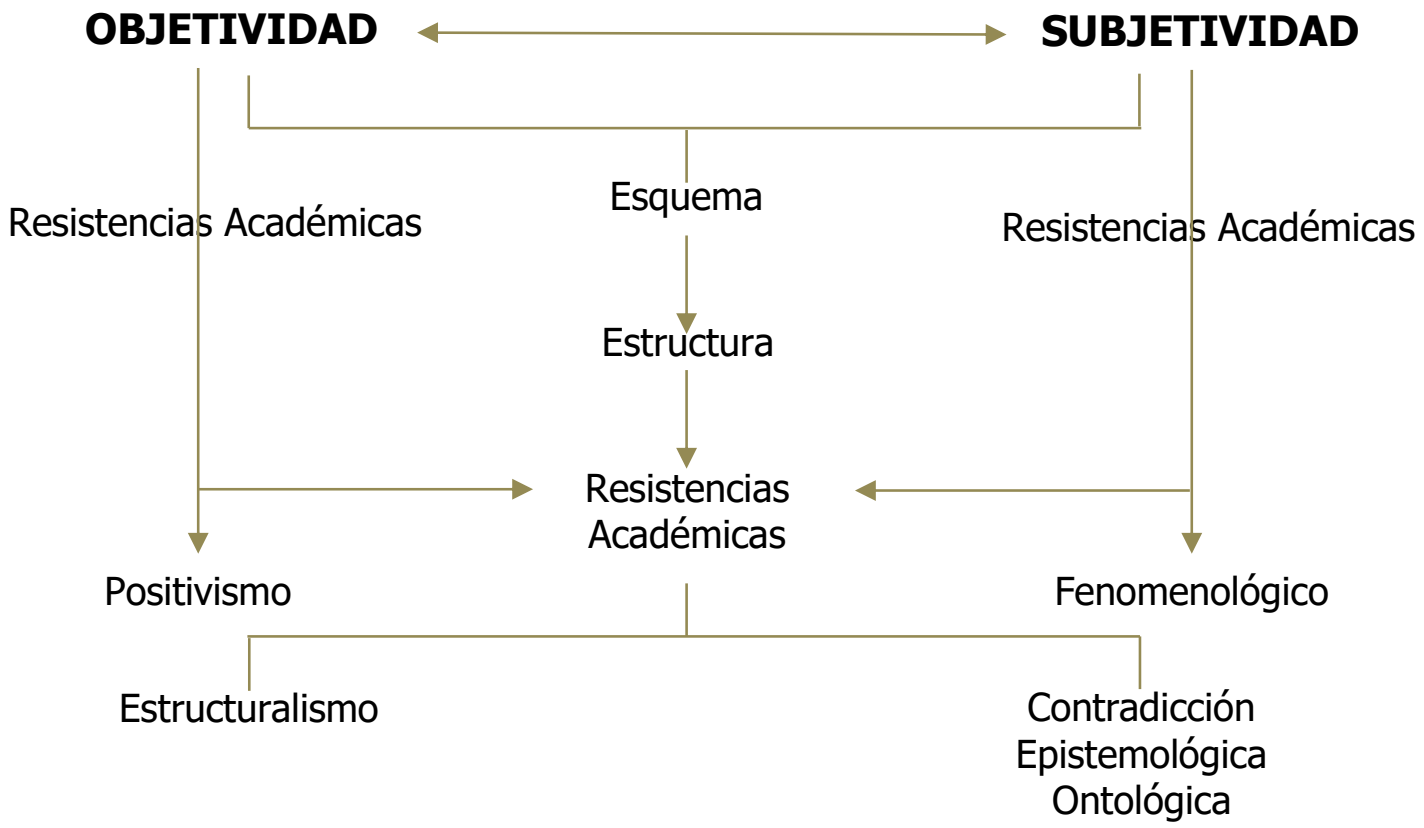

\subsection{El Habitus como una construcción de sujeto con una ontología dialógica entre lo social e individual}

La tercera dimensión refleja dos elementos importantes, a saber: la concepción dinámica entre el sujeto individual vs sujeto social y la exposición de la interiorización de significados en los seres humanos. En cuanto al primer elemento, el habitus ensambla la noción de ser persona, la cual está sujetada a un 
sentido individual. Tal entendimiento, concibe a las personas como "agentes especializados dotados de autoridad" (Rizo, 2006, p. 2).

En efecto, el habitus académico instaura la semiótica creadora de resistencias ónticas en las profesoras, configurando su propio modelo de ser persona, profesional y ciudadana. Lo anterior conceptualiza al otro y a la otra, como actor/actora que desvela su soberanía neoliberal, su capacidad de autocrítica y de adaptabilidad ante las tradiciones culturales en las funciones universitarias.

Dichas personas individualizadas encarnan diversa reflexibilidad, tales como: educativa, política, partidista, religiosa, disciplinar, financiera, científica, gerencial, profesional, gremial, laboral; corporizadas estas, en la identidad de ser un agente social (el ser mujeres con identidad de empleadas, docentes, científicas e intelectuales). Con ello, están implicadas en cierto cambio paradigmático y adaptación al discurso decimonónico subyacente en el habitus en la universidad. Por tanto, el habitus académico es un camino óntico que institucionaliza resistencias neoliberales: individualistas en las profesoras, por considerarlas como individu(os) (masculinos), quienes pertenecen a una élite política e intelectual y, también, por ser representantes de la sabiduría científica.

Aún en la contradicción, el habitus académico es la lógica intersubjetiva sobre el ser individuo, ensamblada en la dinámica social que surge en un contexto territorial e histórico. Vislumbra, entonces, a un colectivo donde el ser individual está presente, pero como una parte fragmentada dentro de un todo. Igualmente, visualiza un conglomerado de personas que se suman para formar un conjunto.

Tal habitus expone un sentido de colectivo que desvela el ser social de los individuos. En este ser, se entretejen las relaciones intersubjetivas -pues comparten los sentidos y espacios comunes- en las realidades sociales de la comunidad. Así, es un camino que establece una identidad de resistencia para mirar a las profesoras como personas sociales e individuales. Esta visión expone aspectos culturales e identitarios relevantes en pro de entender su perspectiva óntica, epistémica y pragmática en las prácticas sociales del mundo universitario. 
En fin, el habitus académico expone las resistencias consensuadas que observan a la profesora, repleta de identidades neoliberales; las cuales se caracterizan por un ser (masculino): solitario, masculinizado, agente, pieza tecnológica para la producción, coproductor tecnocientífico, agente ubicado en un segundo estatus y nivel jerárquico, domesticado, apagado a lo institucional, dependiente, subordinado, carente de soberanía y autonomía, vigilado y garante del gran orden controlador, negado en su condición de trabajadora de la doble jornada, reservado a su función reproductiva heterosexual, entre otras significaciones sustanciales de una identidad heterosexual.

Sin embargo, el habitus académico propone resistencias que valora a las profesoras, desde una visión social. Acá, lo colectivo está determinado por signos identitarios de pluralidad que, a pesar de ser escasos, existen en la textualidad e intertextualidad del discurso institucional con el que ellas interaccionan productiva y cotidianamente.

Dicho habitus comprende que las mujeres mencionadas, se visibilizan por un identidad del nosotros inclusivo en la colectividad del personal docente e investigador. En efecto, están representadas en ese yo-nosotros, porque se usa una identidad de sujeto genérico en los discursos escritos sobre la fundación e institucionalidad universitaria (Meléndez, 2017). Esto enuncia una aparente o superficial diferenciación identitaria con otros colectivos universitarios: personal obrero, administrativo y estudiantado.

En relación con el pensamiento inclusivo, el habitus concibe a las profesoras como personas obligadas a asumir las identidades de maternidad. En consecuencia, persiste un discurso que origina resistencias para identificar a estas mujeres como el colectivo socioproductivo con una discriminación positiva, porque tienen la capacidad de reproducción biológica y de maternidad sociosimbólica.

En el discurso laboral, contractual e institucional, se refleja un habitus donde surgen resistencias, desde donde son observadas como colectivo cercano a un espíritu de común unidad, sustentado en el sentido de comunicación de la vida biológica y la vida social. Lo expuesto posee una representación social, asociada a 
beneficios legales y condiciones institucionales prevalentes en pro de su experiencia de embarazo y maternidad (tiempo de pre y postnatal).

Ahora bien, el segundo elemento de interés es la interiorización de los significados socioculturales que fundamentan el habitus. Según Rizo (2006), el habitus se reconoce como un conocimiento hecho cuerpo, apegado a los esquemas mentales más estructurales y substanciales de la sociedad e individualidad. Por esto, la incorporación es concebida como la capacidad de las personas para realizar la interiorización de las regularidades emergentes en sus condiciones de vida. De allí que, la interiorización puede tener un determinismo en la inclusión de tales regularidades.

Con estas ideas, el habitus académico procrea resistencias constituyendo intersubjetividades (identidades) compartidas por sentidos comunes emergentes en el colectivo de profesoras durante sus prácticas universitarias. El habitus instaura resistencias para entretejer sujeciones ante las racionalidades e interacciones productivas inamovibles que permanecen en el tiempo histórico y espacio social, con la intención de consolidar sus prácticas sociales.

Académicamente, el habitus es el promotor de resistencias que intentan que ellas se apropien de subjetivaciones (identidades) del contexto universitario, que -con un discurso sutil e invisible- dominan y delimitan el sentido óntico, epistémico como práctico de las profesoras.

Al valorar la interiorización de la exterioridad, se considera que el habitus materializa la producción libre de todos las ideas, comportamientos, percepciones, subjetivaciones, manifestaciones; lo cual está delimitado por las fronteras inherentes de las condiciones sociales e históricas particulares de su producción o práctica de acción (Gutiérrez, 2004). El habitus académico, entonces, es un sistema identitario de resistencia que entabla diálogos de saberes a partir de límites expresados en las circunstancias, espacios y tiempos culturales e históricos de reformas neoliberales en los colectivos humanos.

Las profesoras están sujetadas a un habitus que les oprime al formar identidades reveladas en significados y prácticas universitarias. Este discurso de 
vida está inscripto en el sentido decimonónico, moral, católico e ilustrado de la intersubjetividad; instaurada por el gran orden occidental sobre la misión y visión de la universidad. Dichos significados y prácticas están expuestos en el cuerpo legal, jurídico como organizacional de las funciones esenciales, en lo cual se expresan los alcances y deberes de estas actoras.

Desde la mirada de Gutiérrez (2004, p. 294) el habitus es la interiorización de la exterioridad, pues, "...implica suponer que esa interiorización comprende también la incorporación de las relaciones de dominación y dependencia en las que se encuentran posicionados diferencialmente los agentes sociales, es decir, la incorporación de ese poder que es constitutivo de la sociedad." El habitus académico produce resistencias en la vida de las mujeres, porque visibiliza la estructura de la gubernamentalidad y la enunciación de agentes institucionales.

El habitus propicia resistencias en las profesoras al reproducir la subyugación a través del discurso académico y organizacional, rector de las funciones universitarias. Por tanto, el habitus académico genera resistencias porque apoya las formas y sentidos en que se distribuye el ejercicio del poder en la universidad.

Se entiende, entonces, que el habitus académico ensambla subjetividades de apropiación, manteniendo la estética y el orden lógico e histórico de las realidades entretejidas socialmente. Así, es una génesis de resistencias, en cuya intención está que las mujeres mencionadas perciban, valoren y mantengan la identidad del status quo de las situaciones, procesos e interacciones universitarias culturales, políticas e profesionales.

El habitus crea resistencias para que defiendan el sentido y la morfología de fenómenos socioculturales, fundadores de la arquitectura y de la dinámica productiva del mundo universitario. Propone resistencias para que los fenómenos anteriores, no sean susceptibles a cambios sustantivos sino, más bien, que sigan con el proyecto político e ideológico de la Ilustración y del Neoliberalismo; con lo cual se naturalizan, decimonónicamente, los modos de vida productiva de las 
profesoras. Con espíritu de sintetizar lo expuesto, esta dimensión presenta en la Gráfica 3.

\section{Gráfica 3: El Habitus como construcción de sujeto social e individual para las resistencias}

\section{HÁBITUS}

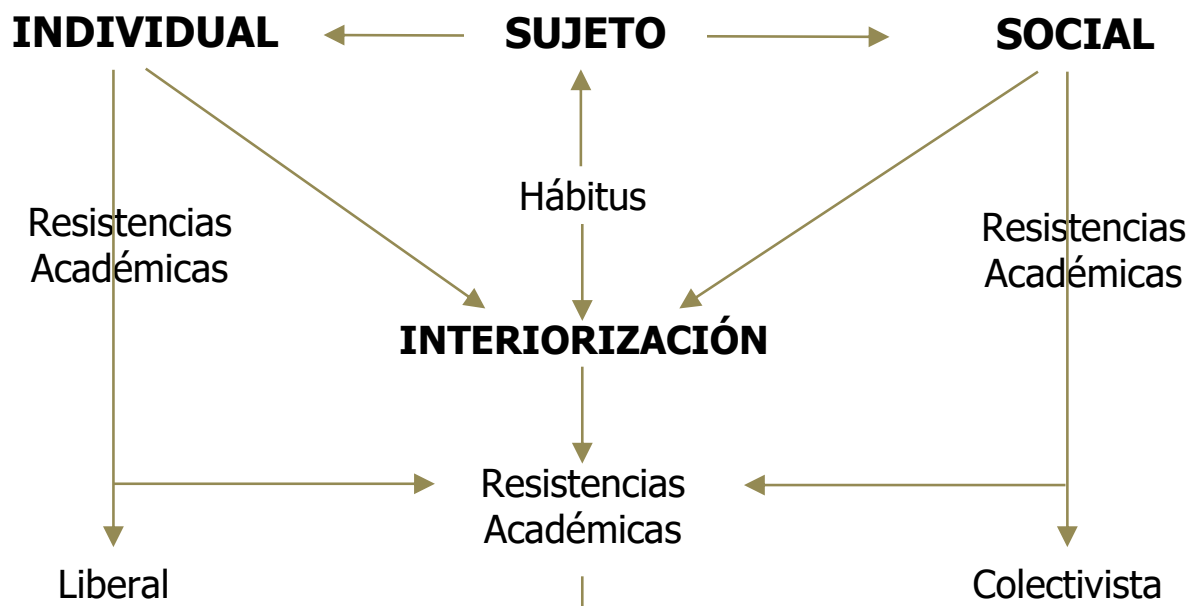

Filosófica, Ideológica, Epistemológica y Praxiológica

Político Partidista, Institucional Universitario, Religioso, Gremial, Científica y Disciplinaria

\subsection{El Habitus como conjunto de prácticas socioculturales}

La cuarta dimensión resignifica al habitus al desvelar dos elementos importantes, a saber: las prácticas sociales y la cultura. En consecuencia, el habitus refiere a las prácticas sociales emergentes para revelar sus cualidades deterministas y reproductivas, referidas a explicar las prácticas sociales escolares y el campo del sistema educativo, como aparato transmisor y reproductor del habitus cargado con identidades diferentes (Rizo, 2006). Por ende, el habitus reproduce identidades en signos, significados e interacciones en la cotidianidad de las mujeres docentes, científicas e intelectuales; lo cual se institucionaliza con la 
educación destinada a prescribir la gestación de identidades sociales con una mirada neoliberal.

Con estas identidades, se justifica -desde una mirada patriarcal- la distribución jerárquica, separatista y sesgada de conceptos, roles, tareas, funciones. En suma, son identidades normadas en las funciones productivas de las profesoras. La distribución de identidades se fortalece en la universidad con la fuerza del heteropatriarcado, porque se sostiene mediante la naturalización de privilegios masculinos y heterosexuales. Privilegios que edifican una jerarquía sexual capaz de reconocer y apalancar distintas corporalidades, expresiones como deseos, en base al género y a la sexualidad (Morán, 2017).

El habitus académico funda resistencias en la consciencia social del colectivo humano y en el discurso meta e intertextual de la estructura académica y organizacional. Tales resistencias pretenden que las profesoras se ajusten al gran orden constituido por varios discursos, a saber: científico, educativo, partidista, político, gremial, religioso, financiero, laboral, gerencial, disciplinar, profesional; siendo estos perpetuados en sus funciones institucionales.

La apropiación y adecuación emerge mediante resistencias que gestan identidades patriarcales, fragmentadas, unidireccionales, estáticas y controladoras en pos de argumentar procesos universitarios básicos. Esto distribuye -en tiempo, espacio y poder-, las corporalidades, racionalidades, emocionalidades e interacciones de los colectivos humanos pero, en especial, del colectivo de profesoras; porque se quiere establecer, dominantemente, una estructura organizativa, estandarizada y obligatoria para regir la producción de sus prácticas sociales.

Según Rizo (2006), el habitus es un elemento que rige la generación y estructuración de las prácticas y representaciones culturales. Esta idea plantea que al habitus académico es un reforzador del gran orden sociopolítico que subyuga mediante la vigilancia, el control, la ubicación, la sanción, el castigo, el silenciamiento, el ocultamiento y la erradicación (asepsia social) de las 
racionalidades e interacciones sociales las profesoras en sus funciones institucionales.

Por tanto, el habitus produce resistencias para defender y fortalecer la dominación patriarcal y capitalista establecida, histórico-materialmente, desde el origen de la universidad. Esta subyugación cultural e institucional se considera como "... el desplazamiento del centro del análisis, tradicionalmente ubicado sobre el individuo homosexual y los actos individuales de discriminación, para ubicarlo en la aplicación institucional de la heterosexualidad normativa y sus consecuencias para las personas no-heterosexuales." (Ventura, 2016, p. 934). Lo anterior, provoca que ellas sean autorreguladoras de las libertades de sus pensamientos y acciones políticas e intelectuales en su vida universitaria cotidiana.

En cuanto a la cultura, como segundo elemento de esta dimensión, Rizo (2006) expone que el fenómeno cultural en movimiento, involucra escenificar los habitus de las personas. Con esta visión, el habitus académico dibuja un espacio performativo, en donde se reiteran, subyugantemente, los signos y significados de manera caótica, emergente e incierta; para así, perpetuar las identidades que sustentan las prácticas sociales. Dicho habitus incita resistencias en la universidad para que las profesoras, por su identidad materializada por su condición histórica, política, estereotipada y discriminada de mujer, implanten una lógica que rige, heteronormativamente, sus prácticas productivas en sus esferas de interacción social.

Esta lógica revela un sentido de dominación, entendido a partir de las ideas de Morán (2017), quien plantea que las feministas negras y subalternas reconocen la obligatoriedad de repensar el patriarcado y a la heteronormatividad intersectados con las categorías de raza, territorialidad o la clase. Si no se incluyen estas dos categorías estructurales, se agudiza la reproducción de imaginarios blancos, de clase media y occidentales; es decir, se instalaría una tipología de habitus heterosexista y racista.

El habitus es un sistema performativo que fusiona, con mucha tensión y contradicción, lo desestructurado, la expresión espontánea, lo controlado por una 
voz superior y repetitiva, así como también, la transgresión e irreverencia de signos, significados y acciones universitarias. Todo esto consolida una cultura universitaria con identidades plurivalentes, destinada a establecer un modo normativo y, por otro lado, un modo anómico en las funciones esenciales de las mujeres mencionadas. Finalmente, esta dimensión se resume en la Gráfica 4.

\section{Gráfica 4: El Habitus como conjunto de prácticas sociales y culturales básicas para las resistencias}

\section{HÁBITUS}

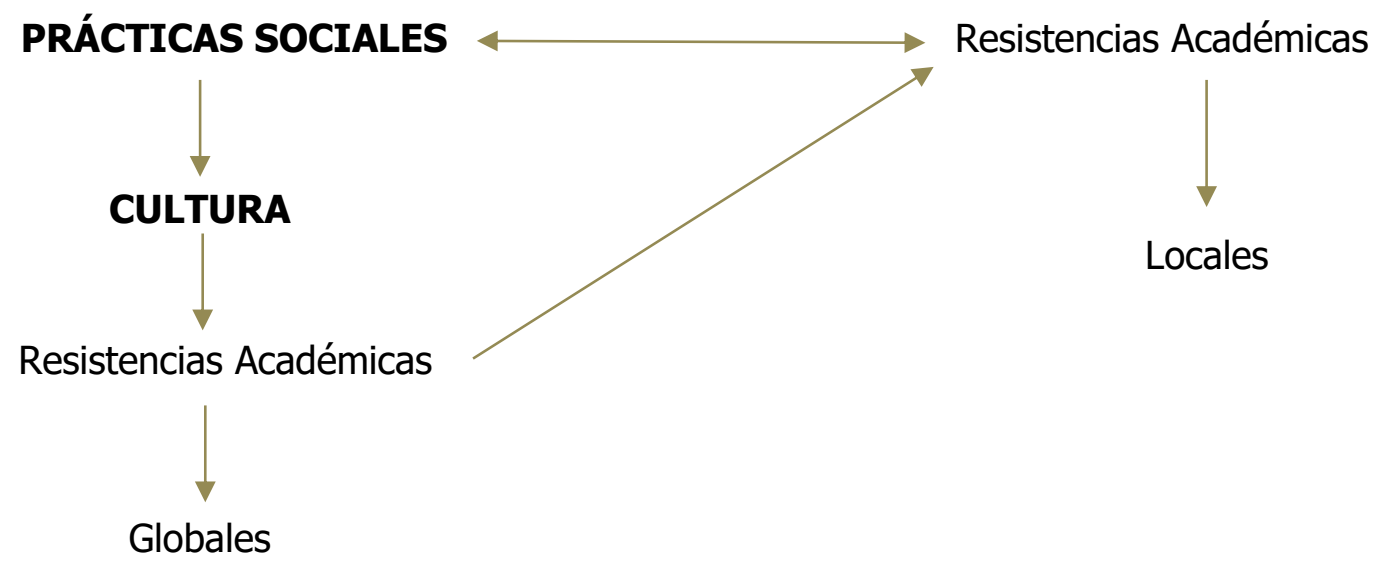

\section{Conclusiones}

Desde una mirada general, el habitus académico como formador de resistencias de las profesoras se interpreta desde las cuatro dimensiones explicadas anteriormente. Esto resalta que el habitus es importante al forjar resistencias de las mujeres, pues petrifica las interacciones sociales, mantiene la dicotomía: objetividad y subjetividad, construye la definición cercada de sujeto y fortalece las prácticas socioculturales. El habitus académico se fortalece como un mecanismo patriarcal clave al producir resistencias neoliberales, porque domina las experiencias, pensamientos, cuerpos e interacciones sociales de las profesoras. En consecuencia, es una categoría fundamental en el estudio de las identidades vistas en las resistencias, porque legitima la afectación de experiencias nuevas y cotidianas que ellas viven en la universidad. 
Partiendo de la mirada académica, el habitus es relevante al vislumbrar las prácticas identitarias de resistencias en las mujeres docentes, científicas e intelectuales, con las cuales se apunta al rechazo y aceptación de discursos ideológicos, tales como el neoliberal. Es urgente incorporarlo en la discusión sobre las resistencias, porque se reconoce como un dispositivo cultural que implanta valoraciones aprehensivas, reactivas y repulsivas (consolidadas o aproximativas) ante los objetos, situaciones, procesos como estructuras que delimitan las funciones esenciales y las estructuras universitarias que afectan a las profesoras.

El habitus es un aparato sociocultural de alta importancia al reconocer la sincronización de identidades materializadas en actitudes de las actoras mencionadas. Esto interpreta la mecanización de las resistencias, en términos de ideas, creencias y formas de saber y conocer, es decir, de identidades; encarnadas estas últimas en su propia formación científica, así como también, en el desarrollo de sus funciones universitarias. Este concepto es fundamental al comprender las resistencias de las mujeres, porque desvela su disposición estética y sus gustos al tomar decisiones propias de su vida productiva universitaria. Entender el habitus académico es primordial, porque denuncia la estética identitaria de la acción opresora en la jerarquización intra e intersubjetiva propia de la lógica neoliberal, emplazada en los modos de vida las profesoras.

Dicho habitus valora las disposiciones morales (identidades) en las interacciones sociales de las profesoras, descubre la obligación política para ser y actuar en la universidad y es indispensable cuando se desvelan las bases/representaciones identitarias de las resistencias que sustentan sus disposiciones duraderas en su trayectoria universitaria. Vislumbrar el habitus académico, implica una perspectiva productiva interesada en estimar la institucionalización de la educación neoliberal que las profesoras reproducen y mantienen en sus funciones y experiencias universitarias. El estudio sobre el habitus revela las resistencias que cimientan el respeto por el status quo que ellas mismas asumen ante la dominación cultural de la universidad, la profesión académica y las funciones institucionales. 
Otra reflexión final es que, el habitus académico es una categoría importante al entender la fuerza del ethos masculino; lo cual actúa como base de resistencias. En este sentido, es un concepto relevante porque evidencia las formas homogéneas y universales de existir, vivir y convivir en la universidad. Con tales formas, se despliega una imposición culturalizada, delimitando el quehacer de las profesoras. En efecto, tal habitus se constituye en la lógica intersubjetiva sobre las resistencias en la cultura universitaria, para funcionar como un mecanismo de ajuste social ante la fuerza del gran orden del discurso científico.

El reconocimiento del habitus revela las resistencias que impeden la diversidad de racionalidades y de acciones, lo cual corresponde a un discurso que procura ser tradicionalista y reducir la capacidad de flexibilidad y creatividad de pensamientos alternos. Analizar al habitus académico es desvelarlo como un proceso legitimado por la ideología de las reformas educativas neoliberales. Esto establece una forma única al originar las resistencias como identidades fracturadas y patriarcales en las profesoras. La comprensión de este habitus, es una oportunidad para interpretar una manera política que distribuye tareas/funciones según la dictaminación polarizada del género sexual machista, repetitivo y heteronormativo; siendo esto, reforzado por la ciencia, los mercados de trabajo capitalistas, la profesionalización, así como también, la vida productiva de las mujeres.

Finalmente, el habitus académico fortalece las representaciones e imaginarios identitarios que institucionalizan un sistema simbólico de resistencias al crear lineal y unidireccionalmente, tanto las teorías como métodos predeterminados por el discurso del gran orden social. Tal habitus es fundamental analizarlo, porque considera que las profesoras despliegan resistencias que consolidan significados en pos de fortalecer la subyugación ideológica de las mujeres. Con esto, se replica un ajuste social para sujetarse ellas mismas y para ajustar, coercitivamente, a las demás personas universitarias frente al patriarcado. Este lógica impone un discurso político e ideológico neoliberal que regula las acciones de las profesoras, encarnándose en múltiples escenarios, a saber: el 
Estado-nación, las normativas existentes en la universidad, los sistemas de gobierno del país; la religiosidad de las Iglesias; las instituciones no gubernamentales globales; el mercado profesional y laboral así como también, las crisis sociales, políticas, económicas e institucionales.

\section{Referencias Bibliográficas}

Bourdieu, P. (1980). El sentido práctico. Madrid: Taurus.

Bourdieu, P. (1999). Las reglas del arte. Génesis y estructura del campo literario. Madrid: Anagrama.

Gutiérrez, A. (2004). Poder, hábitus y representaciones: recorrido por el concepto de violencia simbólica en Pierre Bourdieu. Revista Complutense de Educación. 15(1), 289-300.

Meléndez, L. (2017). La identidad de género como base de la noción de persona desde la injuria patriarcal en discursos rectorales. Cuadernos del CORDICOM. Medios de Comunicación y Género: Nuevas propuestas. Nº 3. Año 2.

Morán, J. (2017). Patriarcado, heteronormatividad y el discurso de la vida del activismo Pro-Vida en la Argentina. Córdoba: Centro de Estudios Avanzados, Universidad de Córdoba.

Moyano, M. y Durango, J. (2016). Discursos heteronormativos y no heteronormativos en aulas de L2 en colegios de Bogotá. Pontificia Universidad Javeriana Licenciatura en Lenguas Modernas Trabajo de Grado. Colombia.

Rizo, M. (2006). Conceptos básicos para pensar lo urbano: el abordaje de la ciudad desde la identidad, el habitus y las representaciones sociales. Bifurcaciones, 6, 1-13. Disponible en www.bifurcaciones.cl

Rizo, M. y Rodríguez, T. (2016). Epistemología y habitus académico en la enseñanza de la investigación Entrevista a Gilberto Giménez Montiel. Andamios. 13(31), 177-197. 
Tabares, C. (2019). Teorías Críticas Feministas: Transgresoras, Creativas: una contribución a los desafíos de la teoría social en América Latina. NORUS. 7(11), 85-112.

Tarabini, A., Curran, M. y Fontdevila, C. (2015). El habitus institucional: Una herramienta teórica y metodológica para el estudio de la cultura escolar. Tempora, 18, 37-58

Vásquez, M. y Carrasco, A. (2017). Género, cuerpo y heteronormatividad. Reflexiones desde la Antropología. Interciencia, 42(9), 616-622.

Ventura, R. (2016). Tendencias de investigación sobre la heteronormatividad en los medios de comunicación. Opción, 32(10), 932-952.

Fecha de recepción: 10 de enero de 2021

Fecha de aceptación: 30 de abril de 2021

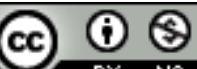

Revista Educación, Política y Sociedad (ISSN 2445-4109) está distribuida bajo una Licencia Creative Commons Atribución-NoComercial 4.0 Internacional 